\title{
VSIMBBTEC
}

Londrina 2015

\section{Permeabilização Celular de Saccharomyces fragilis IZ 275 com Etanol por Metodologia de Superfície e Resposta}

\author{
Luiz Rodrigo Ito Morioka ${ }^{1}$, Cibely Maria Gonçalves ${ }^{1}$, Mayara Karoline Lucatto', \\ Hélio Hiroshi Suguimoto'.
}

${ }^{1}$ Universidade Norte do Paraná, Programa de Pós-Graduação em Ciência e Tecnologia de Leite e Derivados, Caixa Postal 401, CEP 86041 - 140. Londrina - PR, Rua Marselha, 591. E-mail: Irodrigoi@yahoo.com.br.

\section{RESUMO}

O trabalho tem como objetivo verificar a condição ótima para a extração da enzima $\beta$ galactosidase através da permeabilização celular com etanol utilizando a técnica de delineamento experimental associado à Metodologia de Superfície de Respostas. Foram avaliadas três variáveis independentes (concentração de etanol, temperatura e tempo de reação) em função da resposta (atividade enzimática). A permeabilização celular foi melhorada com o aumento da concentração de etanol. Essa abordagem permitiu identificar uma faixa ideal das variáveis independentes em que a atividade da $\beta$-galactosidase foi otimizada. De acordo com os resultados a máxima permeabilização de 11,93 $\mu \mathrm{mol}$ oNP/min foi obtido tratando as células com 23,4\% de etanol a $10^{\circ} \mathrm{C}$ por 20 minutos. A metodologia proposta apresentou ser eficaz e adequado para a permeabilização celular de Saccharomyces fragilis IZ 275 em escala laboratorial com potencial para futuras aplicações, principalmente no setor de alimentos.

Palavras-chave: $\beta$-galactosidase, atividade enzimática, levedura, soro de queijo.

\section{INTRODUÇÃO}

Saccharomyces fragilis é caracterizado como uma levedura homotálico, hemiascomiceto e produtora de diversas enzimas dentre elas a $\beta$-galactosidase (DAGBAGLI; GOKSUNGUR, 2008). Uma característica da $S$. fragilis é a capacidade de assimilar a lactose e utilizar este açúcar como única fonte de carbono por meio da produção de $\beta$-galactosidase. Assim o soro de queijo, fonte de lactose, pode ser usado como meio de cultura para a obtenção da enzima (MARCEL; PASSOS, 2011).

A $\beta$-galactosidase produzida por esta levedura é intracelular, sendo necessária a utilização de técnicas para a extração (COELHO; SALGADO; RIBEIRO, 2008; PANESAR et al., 2007). A permeabilização da parece celular é uma alternativa na qual permite o acesso à composto intracelular. Este método consiste no emprego de agentes que removem a camada fosfolipídica tornando a parede celular porosa, permitindo a passagem de pequenas moléculas (PANESAR, 2008). A permeabilização da parede celular é influenciada por diversos fatores que necessitam ser adequadas. Neste trabalho o delineamento central composto (DCC) foi usado para identificar as condições ótimas para a permeabilização celular de $S$. fragilis IZ 275 utilizando diferentes concentrações de etanol, temperatura e tempo de reação.

\section{MATERIAL E MÉTODOS \\ Soro de queijo}

Universidade Estadual de Londrina - Rodovia Celso Garcia Cid, Pr 445, Km 380 - Campus Universitário Caixa Postal 10.011 CEP 86057-970 Centro de Ciências Exatas - Departamento de Bioquímica e 


\section{SIMPÓSIO DE BIOQUÍMICA E BIOTECNOLOGIA}

\section{VSIMBBTEC}

\section{5 a 07 de agosto de 2015, Londrina - PR}

O soro de queijo em pó (CONFEPAR $R$ ) na formulação integral foi dissolvida em água destilada na concentração de $5 \%(\mathrm{p} / \mathrm{v})$. A desproteinização foi realizada com a adição de solução de ácido láctico (85 \%) até atingir o ponto isoelétrico, $\mathrm{pH} 4,6$, em seguida foi aquecido por 30 minutos a $90^{\circ} \mathrm{C}$. A fração protéica precipitada foi removida por filtração e 0 $\mathrm{pH}$ ajustado para 5,0. A pasteurização do soro de queijo desproteinizado foi a $65{ }^{\circ} \mathrm{C}$ por 30 minutos.

\section{Microrganismo e Condição de cultivo}

A Saccharomyces fragilis IZ 275 foi cultivada durante 48 horas em frasco Erlemneyer com $100 \mathrm{~mL}$ de meio com $5 \%(\mathrm{p} / \mathrm{v})$ de soro de queijo desproteinizado, $\mathrm{pH} \mathrm{5,0} \mathrm{e} 5 \%(\mathrm{v} / \mathrm{v})$ de inóculo no $\mathrm{DO}_{670 \mathrm{~nm}}=0,5$, a $35^{\circ} \mathrm{C}$ e $150 \mathrm{rpm}$. No final da fermentação a cultura foi centrifugada durante 15 minutos a $6000 \mathrm{rpm}$ para obter a biomassa que foi utilizada para as análises posteriores.

\section{Atividade da $\beta$-Galactosidase}

A atividade da $\beta$-Galactosidase das células permeabilizadas foi determinada conforme descrito por Inchaurrondo, Yautorno e Voget, 1994. A atividade da $\beta$-galactosidase foi determinado utilizando o substrato colorimétrico ONPG (orto-nitrofenil- $\beta$-galactosídeo). Uma amostra de $50 \mu \mathrm{L}$ da suspensão celular permeabilizada foi misturada com $2 \mathrm{~mL}$ de ONPG $(1,25 \mathrm{mM})$ em tampão e incubado por 5 minutos a $37^{\circ} \mathrm{C}$. A reação foi interrompida com a adição de $0,5 \mathrm{~mL}$ de carbonato de sódio $(1 \mathrm{M})$. O ONPG liberado foi medido em espectrofotômetro em $A_{420 \mathrm{~nm}}$. Uma unidade de atividade da $\beta$-galactosidase é definido como a hidrólise de $1 \mu \mathrm{mol}$ de ONPG por minuto.

\section{Delineamento estatístico}

O experimento foi realizado conforme delineamento central compost (DCC) com três variáveis com cinco níveis cada $(-1,682,-1,0,1,+1,682)$, Tabela 1 . As variáveis testadas foram: concentração de etanol $(\%)-X_{1}$, temperature $\left({ }^{\circ} \mathrm{C}\right)-X_{2}$ e tempo (min) $-X_{3}$, tendo como resposta a atividade da enzima $\beta$-galactosidase.

\section{RESULTADOS E DISCUSSÃO}

As atividades enzimáticas obtidas através do delineamento variaram de 4,48 até 11,93 $\mu \mathrm{mol}$ oNP/min. A maior atividade de $11,93 \mu \mathrm{mol}$ oNP/min foi obtida na corrida 10 . A condição desta corrida foi: concentração de etanol $(23,4 \%)$, temperatura $\left(10^{\circ} \mathrm{C}\right)$ e tempo $(20 \mathrm{~min})$. De acordo com os resultados obtidos, o coeficiente de determinação $\mathrm{R}^{2}$ foi de 0,93596 que significa 93,596 \% da variação da resposta é explicada pelo modelo, sendo este valor aceitável para sistemas biológicos. A falta de ajuste não foi significativa $(p=0,520750)$, indicando que o modelo proposto para o experimento pode ser utilizado para fins preditivos. 


\section{SIMPÓSIO DE BIOQUÍMICA E BIOTECNOLOGIA}

\section{VSIMBBTEC}

\section{5 a 07 de agosto de 2015, Londrina - PR}

Londrina 2015

Tabela 1. Matriz do delineamento central composto para atividade da $\beta$-galactosidase.

\begin{tabular}{|c|c|c|c|c|}
\hline Corrida & $\begin{array}{c}\text { Concentração } \\
\left(\mathbf{X}_{1}\right)\end{array}$ & \begin{tabular}{|c|} 
Temperatura \\
$\left(\mathbf{X}_{2}\right)$
\end{tabular} & $\begin{array}{c}\text { Tempo } \\
\left(X_{3}\right)\end{array}$ & \begin{tabular}{|c}
$\begin{array}{c}\text { Atividade da } \beta \text {-Galactosidase } \\
(\mu \mathrm{mol} \text { oNP } / \mathrm{min})\end{array}$ \\
\end{tabular} \\
\hline 1 & -1 & -1 & -1 & 6,25 \\
\hline 2 & -1 & -1 & 1 & 5,53 \\
\hline 3 & -1 & 1 & -1 & 5,07 \\
\hline 4 & -1 & 1 & 1 & 6,53 \\
\hline 5 & 1 & -1 & -1 & 10,23 \\
\hline 6 & 1 & -1 & 1 & 9,23 \\
\hline 7 & 1 & 1 & -1 & 11,11 \\
\hline 8 & 1 & 1 & 1 & 10,19 \\
\hline 9 & $-1,682$ & 0 & 0 & 4,48 \\
\hline 10 & 1,682 & 0 & 0 & 11,93 \\
\hline 11 & 0 & 1,682 & 0 & 7,21 \\
\hline 12 & 0 & 1,682 & 0 & 6,40 \\
\hline 13 & 0 & 0 & $-1,682$ & 7,65 \\
\hline 14 & 0 & 0 & 1,682 & 6,81 \\
\hline 15 & 0 & 0 & 0 & 6,38 \\
\hline 16 & 0 & 0 & 0 & 7,43 \\
\hline 17 & 0 & 0 & 0 & 7,34 \\
\hline 18 & 0 & 0 & 0 & 7,82 \\
\hline 19 & 0 & 0 & 0 & 8,08 \\
\hline 20 & 0 & 0 & 0 & 6,42 \\
\hline
\end{tabular}

A concentração de etanol apresentou efeito linear positivo significativo $(p=0,000089)$ a $95 \%$ de confiança; a concentração de etanol (efeito quadrático), a temperatura (efeito linear) e o tempo (efeito quadrático) apresentaram um efeito positivo, ou seja, ao passar do nível -1 (menor concentração) para o nível +1 (maior concentração), houve incremento na atividade enzimática, já a temperatura (efeito quadrático) e o tempo (efeito linear) apresentaram efeito negativo, ou seja, ao passar do nível -1 para o nível +1 , houve diminuição da atividade. As interações $1 \mathrm{~L} / 2 \mathrm{~L}$ e $2 \mathrm{~L} / 3 \mathrm{~L}$ apresentaram um efeito linear positivo não significativo, já a interação $1 \mathrm{~L} / 3 \mathrm{~L}$ apresentou um efeito linear negativo não significativo.

(a)

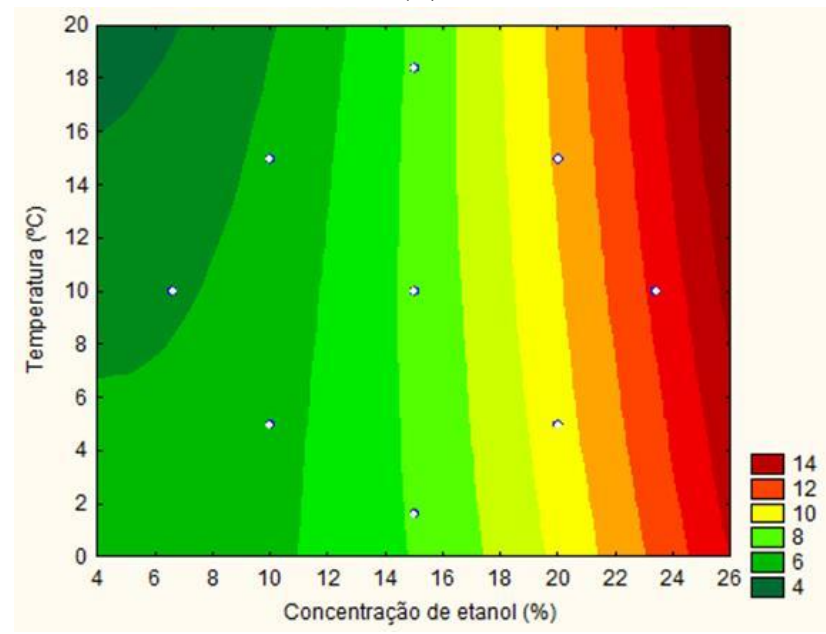

(b)

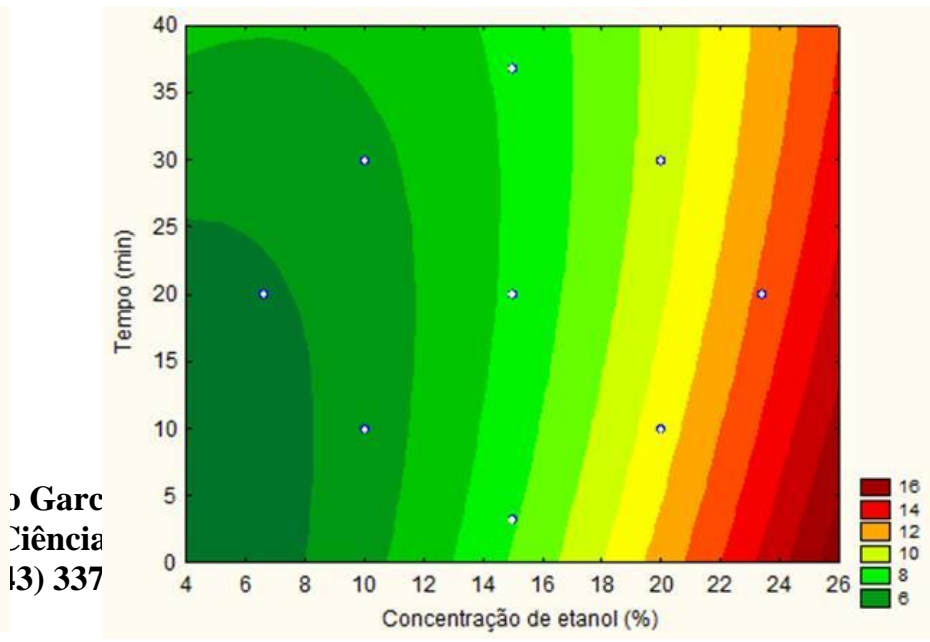




\section{SIMPÓSIO DE BIOQUÍMICA E BIOTECNOLOGIA}

\section{5 a 07 de agosto de 2015, Londrina - PR}

\section{VSIMBBTEC}

(c)

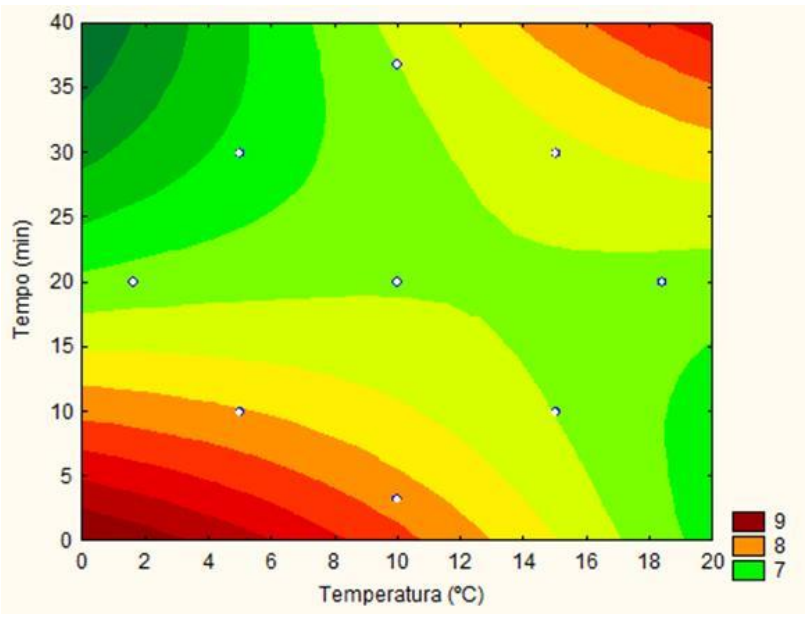

Figura 2. Superfícies de respostas para a atividade de $\beta$-galactosidase em função: (a) temperatura e concentração de etanol; (b) tempo e concentração de etanol; (c) tempo e temperatura.

Pode-se observar na Figura 2(a) que as concentrações de etanol entre 20 e $23,4 \%$ e temperatura entre 5 e $18{ }^{\circ} \mathrm{C}$ conduzem a valores de atividade enzimática superiores a 11,11 $\mu \mathrm{mol}$ oNP/min. Trawczyńska \& Wójcik (2014), observaram que o efeito da concentração de álcool isopropil $(53,7 \%)$, temperatura $\left(15,6^{\circ} \mathrm{C}\right)$ e tempo (40 minutos) de tratamento sobre a permeabilização de células de levedura influenciaram diretamente sobre a atividade enzimática. A Figura 2(b) indica que concentrações de etanol entre 20 e 23,4 \% e tempo na faixa de 3,2 a 20 minutos propiciam altos valores de atividade enzimática. Pela Figura 2(c) observa-se que as maiores atividades são obtidas ao empregar temperaturas entre 2 e $10{ }^{\circ} \mathrm{C}$ e tempo entre 3,2 e 20 minutos.

Agência de Fomento: Coordenação de Aperfeiçoamento de Pessoal de Nível superior Capes.

\section{CONCLUSÃO}

De acordo com os resultados a máxima permeabilização de $11,93 \mu \mathrm{mol}$ oNP/min foi obtido tratando as células com $23,4 \%$ de etanol a $10^{\circ} \mathrm{C}$ por 20 minutos. A metodologia proposta apresentou ser eficaz e adequado para a permeabilização celular de $S$. fragilis IZ 275.

\section{REFERÊNCIAS}

COELHO, M. A. Z.; SALGADO, A. M.; RIBEIRO, B. D. Tecnologia enzimática. Editora EPUB, Rio de Janeiro, Brasil, 2008.

DAGBAGLI, S.; GOKSUNGUR, Y. Optimization of $\beta$-galactosidase production using Kluyveromyces lactis NRRL Y8279 by response surface methodology. Electronic Journal of Biotechnology, v. 11, p. $11-12,2008$.

MARCEL, J. R. P.; PASSOS, F. M. L. Solvent extraction of $\beta$-galactosidase from Kluyveromyces lactis yields a stable highly active enzyme preparation. Journal of Food Biochemistry, v. 35, p. 323 - 336, 2011.

PANESAR, P. S. Application of response surface methodology in the permeabilization of yeast cells for lactose hydrolysis. Biochemical Engineering Journal, v. 39, p. $91-96,2008$.

PANESAR, P. S. et al. Permeabilization of Yeast Cells with Organic Solvents for $\beta$-galactosidase Activity. Research Journal of Microbiology. India, v. 2, n. 1, p. 34-41, 2007.

TRAWCZYNSKA I., WÓJCIK, M. Application of Response Surface Methodology for optimization of permeabilization process of baker's yeast. Polish Journal of Chemical Technology, v. 16, n. 2, p. $31-35,2014$.

Universidade Estadual de Londrina - Rodovia Celso Garcia Cid, Pr 445, Km 380 - Campus Universitário Caixa Postal 10.011 CEP 86057-970 Centro de Ciências Exatas - Departamento de Bioquímica e 